
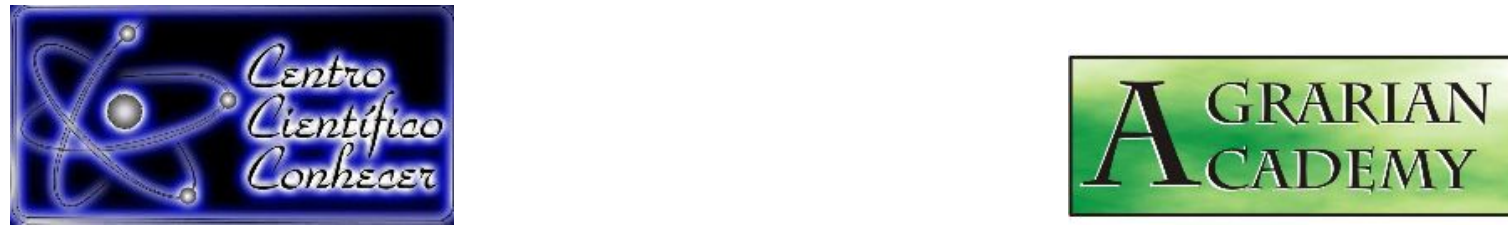

\title{
PLANTAS TÓXICAS A BOVINOS: ANÁLISE DOS PROCESSOS DE DISPERSÃO E REGENERAÇÃO DAS ESPÉCIES
}

Glauciana da Mata Ataíde ${ }^{1}$, Aderbal Gomes da Silva ${ }^{1}$, Marcone Moreira Santos ${ }^{2}$

${ }^{1}$ Prof. Adjunto, Universidade Federal de São João del-Rei, Sete Lagoas, Brasil. E-mail: glauciana@ufsj.edu.br

${ }^{2}$ Prof. Adjunto, Universidade Federal Rural de Pernambuco, Recife, Brasil.

Recebido em: 02/06/2019 - Aprovado em: 15/06/2019 - Publicado em: 22/07/2019 DOI: 10.18677/Agrarian_Academy_2019a24

\begin{abstract}
RESUMO
A intoxicação por plantas é sabidamente uma das principais causas de morte de bovinos adultos no Brasil. As plantas tóxicas são caracterizadas como todos os vegetais que, introduzidos no organismo dos homens ou de animais domésticos, são capazes de causar danos à saúde e vitalidade desses seres. O presente estudo teve como objetivo pesquisar as principais plantas tóxicas potencialmente causadoras de enfermidades a bovinos, identificando os mecanismos de dispersão dessas espécies e propondo alternativas para minimizar os efeitos negativos aos animais. Foram descritas cinco espécies causadoras de danos a bovinos, quais sejam: Palicourea marcgravii, Mascagnia rigida, Tetrapterys acutifolia, Pteridium aquilinum e Cestrum laevigatum, abordando especialmente seus processos de dispersão e regeneração. Conclui-se que a compreensão da dispersão das sementes, aliada ao conhecimento das características de regeneração e propagação das plantas apresenta-se como uma ferramenta útil para a conservação/manutenção de áreas sem infestação por estas plantas.
\end{abstract}

PALAVRAS-CHAVE: danos a bovinos, Intoxicação; propagação de plantas.

\section{TOXIC PLANTS TO CATTLE: ANALYSIS OF DISPERSAL AND REGENERATION PROCESSES OF SPECIES}

\footnotetext{
ABSTRACT

Intoxication by plants is known to be one of the main causes of death of adult cattle in Brazil. Toxic plants are characterized as all plants which are capable of causing harm to the health and vitality of human bodies or domestic animals. The present study aimed to investigate the main toxic plants potentially causing bovine diseases, identifying the mechanisms of dispersion of species and proposing alternatives to minimize negative effects on animals. Five species of plants have been described, namely: Palicourea marcgravii, Mascagnia rigida, Tetrapterys acutifolia, Pteridium aquilinum and Cestrum laevigatum, addressing, specially their dispersal and regeneration processes. It is concluded that an understanding of seed dispersal, AGRARIAN ACADEMY, Centro Científico Conhecer - Goiânia, v.6, n.11; p. 246 2019
} 
together with knowledge of the characteristics of plant regeneration and propagation, is a useful tool for the conservation / maintenance of areas without infestation by these plants.

KEYWORDS: Intoxication; plant propagation; damage to cattle.

\section{INTRODUÇÃO}

A atividade pecuária representa um importante segmento da economia brasileira, servindo como fonte de renda para produtores de diferentes níveis tecnológicos. Segundo Dias-Filho (2014), estima-se que a grande maioria das pastagens brasileiras apresenta algum estado de degradação, o que, por causar esgotamento da forrageira de interesse, permite a infestação por plantas daninhas.

Tais plantas concorrem com as forrageiras em termos de luz, água, nutrientes e espaço físico (IKEDA; INOUE, 2015). Dentre essas plantas, têm-se aquelas que, além do inconveniente dentro do ambiente, podem ainda causar distúrbios aos animais, que são as plantas tóxicas invasoras de pastagens (FRANCISCHINI et al., 2018). As plantas tóxicas são caracterizadas como todos os vegetais que, introduzidos no organismo dos homens ou de animais domésticos, são capazes de causar danos à saúde e vitalidade desses seres (DINIZ et al., 2017). No Brasil, o número de plantas conhecidas como tóxicas para ruminantes e equinos aumenta constantemente, já tendo sido descritas mais de 100 espécies tóxicas, pertencentes à pelo menos 50 gêneros (RIET-CORREA; MEDEIROS, 2001).

Carvalho et al. (2009) relatam que as intoxicações por plantas são as causas mais frequentes de mortes súbitas a bovinos em todo o Brasil. Intoxicações por plantas em animais de produção são apontadas como causas importantes de prejuízos econômicos na pecuária em diversas regiões do Brasil (ESTIMA-SILVA et al., 2016). Em geral, os animais que ingerem essas plantas morrem de maneira repentina, sem sinais clínicos prévios, ou com sintomas que passam despercebidos (HELAYEL et al., 2009), dificultando o atendimento aos animais após intoxicação.

O desconhecimento das espécies vegetais tóxicas é apontado como o principal fator para ocorrência desses acidentes, de modo que informações técnicas sobre a dispersão, regeneração e aspectos reprodutivos e fenológicos dessas espécies são fundamentais para a prevenção e mitigação do problema. As principais famílias botânicas representantes de plantas tóxicas aos bovinos são Rubiaceae, Bignoniaceae e Malpighiacae, dentro das quais é possível destacar plantas com princípios tóxicos e ações patológicas distintas (GONZALEZ, 2010).

Neste contexto, o presente estudo teve como objetivo pesquisar as principais plantas tóxicas potencialmente causadoras de enfermidades a bovinos, identificando os mecanismos de dispersão dessas espécies e propondo alternativas para minimizar os efeitos negativos aos animais.

\section{Principais plantas tóxicas que acometem os bovinos}

Devido ao grande número de espécies, as plantas tóxicas apresentam variações de acordo com a divisão regional, com a ação patológica, com as famílias botânicas ou com os princípios tóxicos. As principais plantas tóxicas que acometem os bovinos podem ser visualizadas no Quadro 1 e serão descritas a seguir (RIETCORREA; MEDEIROS, 2001). 
QUADRO - 1. Principais plantas tóxicas causadoras de enfermidades em bovinos com potencial de ocorrência no Brasil.

\begin{tabular}{|c|c|c|c|c|}
\hline Família & Nome científico & $\begin{array}{c}\text { Nome } \\
\text { popular }\end{array}$ & Incidência & Princípio ativo \\
\hline Rubiaceae & $\begin{array}{l}\text { Palicourea } \\
\text { marcgravii }\end{array}$ & $\begin{array}{l}\text { erva de rato, } \\
\text { cafezinho }\end{array}$ & $\begin{array}{l}\text { N, NE, } \\
\text { CO, SE }\end{array}$ & $\begin{array}{c}\text { Ácido } \\
\text { monofluoracetato } \\
\text { de sódio }\end{array}$ \\
\hline Malpighiaceae & Mascagnia rigida & corona & $\mathrm{CO}, \mathrm{SE}$ & Cromonas \\
\hline Malpighiaceae & $\begin{array}{c}\text { Tetrapterys } \\
\text { acutifolia }\end{array}$ & cipó-ruão & SE & desconhecido \\
\hline Polypodiaceae & $\begin{array}{l}\text { Pteridium } \\
\text { aquilinum }\end{array}$ & samambaia & $\begin{array}{l}\text { todo } 0 \\
\text { Brasil } \\
\end{array}$ & Ptaquilosídeo \\
\hline Solanaceae & $\begin{array}{c}\text { Cestrum } \\
\text { laevigatum }\end{array}$ & coerana & $\mathrm{SE}, \mathrm{NE}$ & Saponinas \\
\hline
\end{tabular}

\section{Palicourea marcgravii St. Hil.}

Conhecida popularmente como erva-de-rato, café-bravo, cotó-cotó ou tangará-açu, Palicourea marcgravii é uma planta nativa do Brasil pertencente à família botânica Rubiaceae, ocorrendo em praticamente todo o território brasileiro, com exceção apenas da região Sul e do Estado do Mato Grosso do Sul. (D'OLIVEIRA et al., 2018a). P. marcgravii é um arbusto de caule lenhoso, nodoso e quebradiço, semelhante ao bambu, que pode atingir até três metros de altura, porém geralmente não passa de dois metros (D'OLIVEIRA et al., 2018a) (Figura 1).
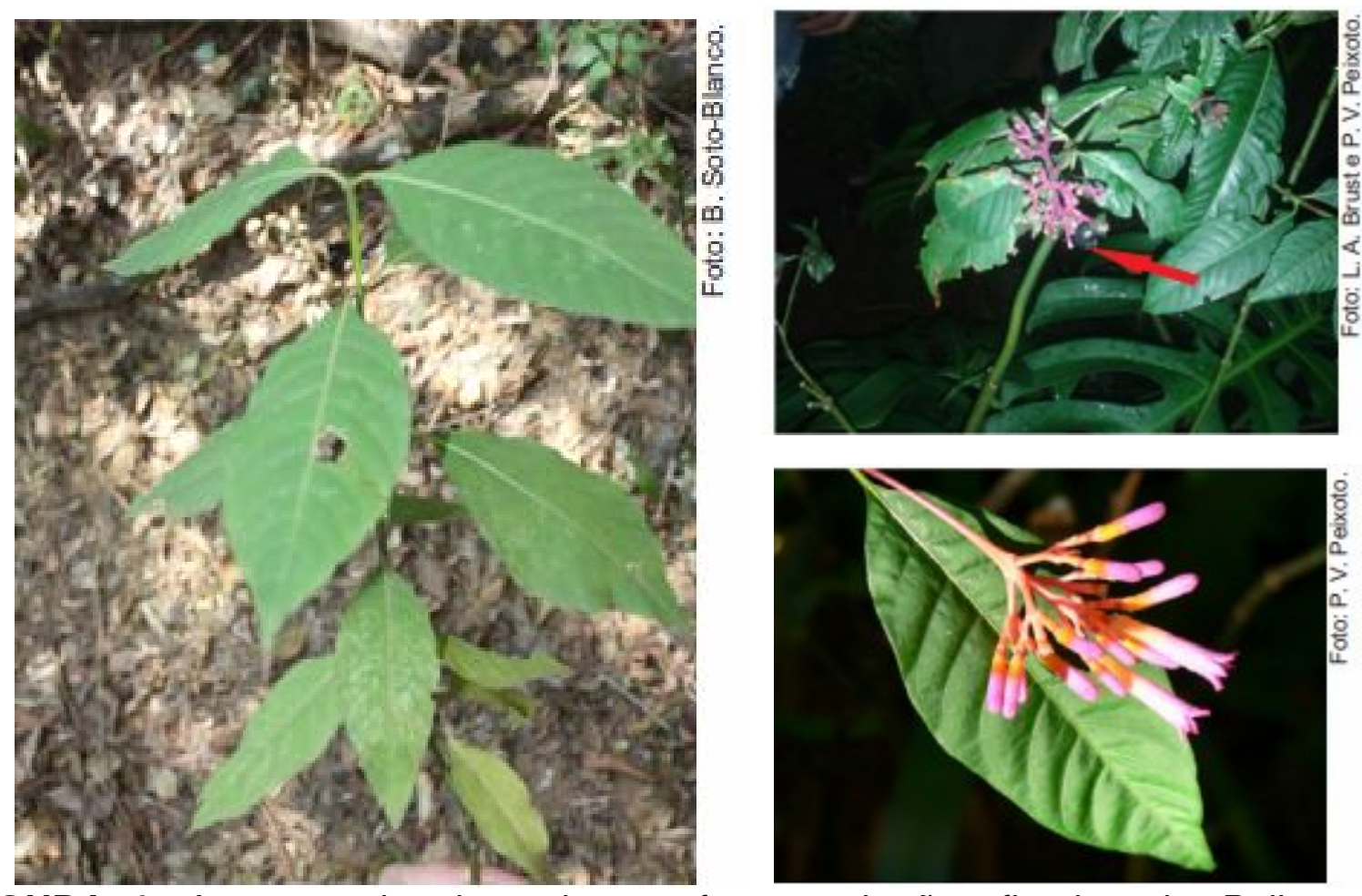

FIGURA 1. Aspectos da planta jovem, frutos e botões florais de Palicourea marcgravii. FONTE: D'Oliveira et al. (2018a). 
A espécie habita regiões de boa pluviosidade e terra firme, jamais ocorrendo em locais de várzea. Segundo Helayel et al. (2009), a planta não sobrevive muito tempo em pastagens limpas, onde fica exposta ao sol, necessitando de sombra parcial para seu crescimento, tais como beira de matas e em capoeiras (HELAYEL et al., 2009). Dessa forma, a ingestão acidental dessa planta pelos bovinos ocorre quando os mesmos adentram em matas ou quando estas são devastadas para a formação de pastos, ocasião em que ocorre uma grande proliferação da Palicourea marcgravii, aumentando assim os riscos de intoxicação (TOKARNIA et al., 2000).

$P$. marcgravii é a planta tóxica mais importante para bovinos no Brasil, em decorrência da sua extensa distribuição, palatabilidade e toxidez alta e o efeito acumulativo (BARBOSA et al., 2015; CARDOSO et al., 2017; D'OLIVEIRA et al., 2018a; KOETHER et al., 2019). As partes da planta que causam intoxicação aos animais são as folhas e os frutos, os quais possuem como princípio ativo o ácido monofluoracético (MENDONÇA et al., 2017). O monofluoracético de sódio interfere no metabolismo celular, inibindo o ciclo de Krebs e provocando diminuição na produção de ATP em até 50\% (TOKARNIA et al., 2000), sendo o sistema o sistema nervoso o principal alvo afetado pela Palicourea marcgravii.

Barbosa et al. (2003) constataram que, após ingestão de folhas de $P$. marcgravii, o período entre o aparecimento dos sintomas graves e a morte de bovinos foi de 9 a 17 minutos. Após intoxicação, o tratamento curativo é inviável, devido à natureza superaguda da evolução do quadro clínico da intoxicação (RUGGIERI et al., 2010).

A propagação da espécie é feita por sementes e sua dispersão é zoocórica, sendo polinizada por duas espécies de beija-flor (Chlorostilbon lucidus e Phaethornis pretrei) (MACHADO et al., 2007). Segundo os autores, $P$. marcgravii possui floração longa e contínua durante os meses do ano, tanto na estação seca quanto chuvosa. Dessa forma, considerando-se os aspectos propagativos da espécie, a floração sequencial é uma estratégia reprodutiva de $P$. marcgravii, pois garante a permanência dos beija-flores polinizadores continuamente na área, aumentando as chances de dispersão de novas sementes e, consequentemente, de infestação das pastagens.

Tal comportamento corrobora com as informações de Carvalho et al. (2009) e Ruggieri et al. (2010), que indicam que a planta é ingerida em qualquer época do ano pelos bovinos, apesar do número maior de intoxicações ocorrer no período de seca, quando os animais penetram nas matas e capoeiras.

Assim, as estratégias para eliminação e controle dessas plantas devem ser integradas continuamente durante todo $\mathrm{o}$ ano, com a completa erradicação das plantas. Para a retirada das plantas, podem ser feitos o arranquio manual, roçadas ou capinas. Adicionalmente, novos estudos devem ser conduzidos visando expandir as informações sobre medidas de controle da espécie, citando-se como exemplo o desenvolvimento de herbicidas que atuem inibindo a germinação das sementes e, consequentemente, o processo de regeneração da espécie nas áreas de pastagens.

\section{Mascagnia rigida (A. Juss) Griseb.}

O gênero Mascagnia, pertencente à família Malphigiaceae, apresenta três espécies de plantas tóxicas importantes a bovinos: $M$. cartaceae, $M$. publifora e $M$. rigida, as quais ocorrem desde o Nordeste até o Norte de Santa Catarina (RUGGIERI et al., 2010). Destas, M. rigida, conhecida pelos nomes vulgares de "tingui" e "timbó"; "pelabucho" e "quebra-bucho" (Bahia); "salsa rosa" e "rama- 
amarela" (Minas Gerais); "suma-branca" e "suma-roxa" (Espírito Santo) (TOKARNIA et al., 2000), tem sido relatada como a principal, sendo responsável por casos de morte súbita a bovinos nas regiões Centro Oeste e Sudeste do Brasil.

M. rigida é um cipó arbustivo com folhas elípticas, opostas, sem pelos, inflorescência em cachos, axilar e terminal com flores pequenas e amarelas (TOKARNIA et al., 2000; D'OLIVEIRA et al., 2018b) (Figura 2).

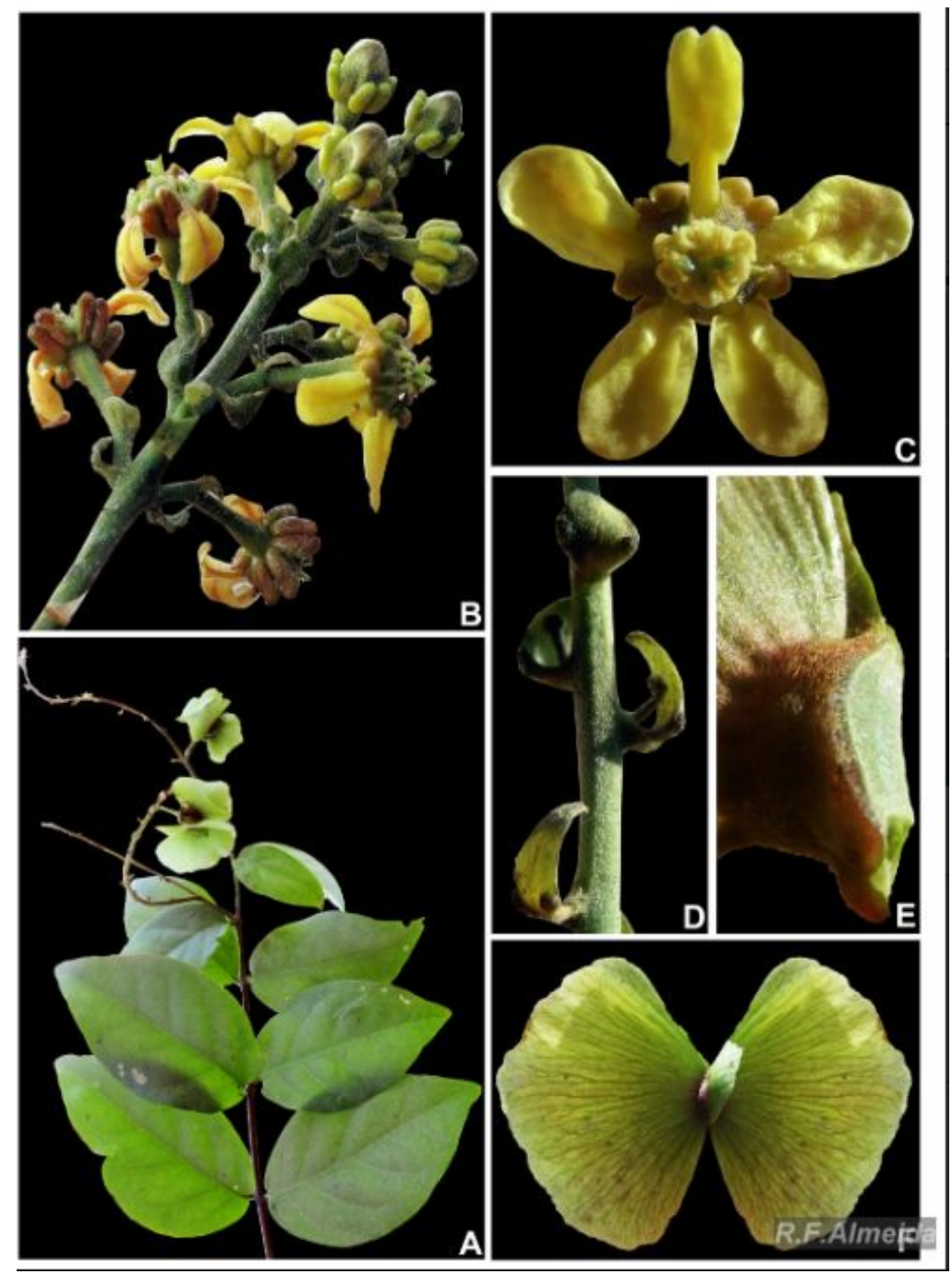

FIGURA 2. Aspectos das flores, inflorescência, folhas e sementes de Mascagnia rígida. FONTE: REFLORA/JBRJ (2016).

O princípio tóxico da espécie deve-se à presença de monofluoroacetato em extratos foliares de $M$. rigida. A ação do monofluoroacetato, ou ácido monofluoracético, baseia-se na formação de fluorocitrato, seu metabólito ativo, que bloqueia competitivamente a aconitase e o ciclo de Krebs, reduzindo a produção de ATP e provocando distúrbios no coração e sistema nervoso central dos animais (NASCIMENTO et al., 2018).

De acordo com Gava et al. (2008), os bovinos ingerem as folhas dessa trepadeira quando esta é encontrada em capoeiras e em locais de desmatamento 
recente, quando ocorre muita brotação da planta, enquanto em locais de mata os ramos de Mascagnia sp. se estendem sobre a copa das árvores, ficando fora do alcance do gado. A morte súbita dos animais ocorre entre 24 e 48 horas após a ingestão da planta, sendo a evolução da intoxicação até a morte entre 40 a 75 minutos após o início dos sintomas (GAVA et al. 2008). Os animais morrem por insuficiência cardíaca aguda, à semelhança do que acontece com a intoxicação por Palicourea marcgravii.

A propagação de $M$. rigida é feita por sementes (CARVALHO et al., 2009), mas a espécie também se propaga por meio de rizomas. O sistema radicular é bastante desenvolvido, visto que se desenvolvem bem em regiões secas e rebrotam facilmente depois de roçadas.

As sementes de Mascagnia sp. são dispersas por anemocoria (BATTILANI, 2010). Em estudo sobre chuva de sementes em trecho de floresta ripária no Mato Grosso do Sul, Battilani (2010) verificou que as sementes de Mascagnia sp. foram as mais abundantes entre as lianas, representando cerca de $34 \%$ do total das sementes de lianas na chuva de sementes, com padrão temporal contínuo de dispersão das sementes, porém apresentando picos em março e outubro, final e início da estação chuvosa, respectivamente.

A dose letal para bovinos varia amplamente em relação ao estádio de crescimento da planta (ROSSETTI; CORSI, 2009). Segundo os autores, nos últimos meses da estação seca, ou seja, quando a planta está em brotação, floração e frutificação, geralmente a dose letal é de $5 \mathrm{~g}$ de folhas frescas por $\mathrm{kg}$ de peso corporal, enquanto no final da estação chuvosa, quando a planta está madura, geralmente, a dose letal é de $20 \mathrm{~g} / \mathrm{kg}$.

Neste contexto, a dispersão anemocórica e a manutenção de sementes no banco de sementes podem explicar, pelo menos parcialmente, a maior severidade de intoxicação a animais no final da estação seca. Nesta, as condições climáticas são mais favoráveis para a dispersão das sementes anemocóricas, as quais germinam e se regeneram, amadurecendo até a próxima estação. Além disso, na época da seca, as folhas de $M$. rigida caem no solo, facilitando o acesso dos animais, quando os compostos tóxicos podem atuar de forma mais ativa.

Para minimizar os riscos de intoxicação com $M$. rigida, por meio do controle da dispersão da espécie, recomenda-se eliminar plantas da espécie encontradas em faixas de vegetação próximas às pastagens e construção de aceiros ao redor das áreas. Aos bovinos, podem ser citados cuidados especiais no início das chuvas e após o período das chuvas, se possível retirando os animais das áreas de risco durante esses períodos e removendo as plantas do local.

\section{Tetrapterys acutifolia Cav.}

Tetrapterys acutifolia é uma planta arbustiva conhecida como "cipó-ruão" e "cipó-preto" pertencente à família Malpighiaceae, sendo uma planta tóxica importante em algumas áreas da região Sudeste, causando mortes em rebanhos bovinos em regiões como o vale do Paraíba, em São Paulo, e Governador Valadares, em Minas Gerais (CARVALHO et al., 2009). A espécie é uma planta viçosa, com folhas de coloração verde bem evidente, com inflorescência sob a forma de panícula, com flores amarelas que quando frutificam adquirem coloração marromavermelhada (TOKARNIA et al., 2000). 

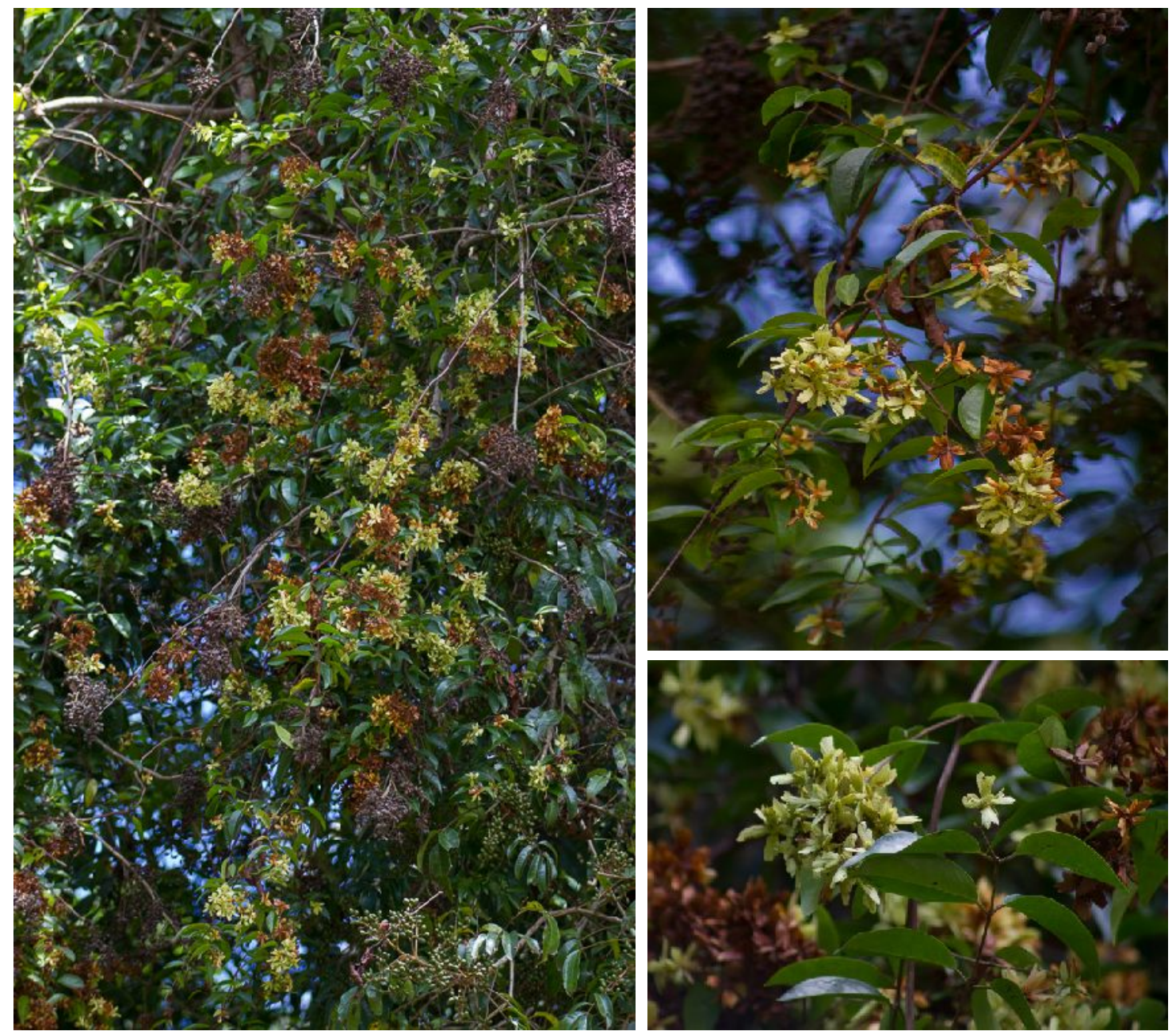

FIGURA 3. Aspectos do arbusto, folhas e inflorescências de Tetrapterys acutifolia. FONTE: Flore de Guyane (2016).

O princípio tóxico de $T$. acutifolia está nas folhas verdes, as quais possuem heterosídeos flavônicos, taninos condensados, alcalóides quaternários e esteróides (FERNANDES, 2016). Sanches et al. (2011), estudando o fracionamento do extrato de folhas da espécie identificaram a presença das substâncias $\beta$-sitesterol, estigmasterol, ácido ascórbico 2,6 dipalmitato e 5,6-diidro- $\beta$-sitosterol.

Segundo Carvalho e Arruda (2011), os sinais de intoxicação por T. acutifolia estão relacionados à insuficiência cardíaca: veia jugular ingurgitada, pulso venoso positivo, edema da região da barbela, arritmia cardíaca, edema esternal (peito inchado), dificuldade de locomoção, fraqueza e anorexia, tremores musculares e fezes ressequidas. A ingestão de $T$. acutifolia possui ainda efeito abortivo para bovinos, a insuficiência cardíaca causada por dano direto do princípio tóxico da planta ao miocárdio da vaca gestante atravessa a barreira placentária, de forma que o aborto ocorre em qualquer fase da gestação.

As intoxicações ocorrem durante todo o ano (CARVALHO et al., 2009), porém, experimentalmente comprovou-se que as intoxicações ocorrem mais na época seca, quando o gado ingere a brotação da planta, sendo esta responsável pela intoxicação natural (TOKARNIA et al., 2000).

Jacobi e Carmo (2011) descrevem que T. acutifolia possui dispersão por anemocoria e polinização preferencial entomófila, tendo como fisionomia AGRARIAN ACADEMY, Centro Científico Conhecer - Goiânia, v.6, n.11; p. 252 
predominante as áreas abertas. A presença de $T$. acutifolia foi constatada em áreas de campos rupestres na região do quadrilátero ferrífero de Minas Gerais, especialmente em Mariana e em restingas no estado de São Paulo.

À semelhança do padrão observado para Mascagnia rigida, a dispersão anemocórica de $T$. acutifolia pode contribuir para a infestação dessa espécie em pastagens, principalmente em áreas próximas a formações florestais, como matas e capoeiras e na época seca, quando ocorrem ventos mais fortes e constantes.

Visando à redução da ocorrência de $T$. acutifolia, recomenda-se a erradicação da planta dos pastos e o isolamento das áreas onde exista a planta (TOKARNIA et al., 2000), além de práticas culturais para eliminação das sementes da espécie presentes no banco de sementes do solo.

\section{Pteridium aquilinum (L.) Kuhn}

Planta da família Polypodiaceae conhecida popularmente como samambaia ou samambaia-do-campo, Pteridium aquilinum é uma pteridófita rasteira encontrada em todo o Brasil (BRANDÃO et al., 2017), sendo evidenciados surtos de intoxicação a bovinos em todas as regiões do país (RUGGIERI et al., 2010). P. aquilinum habita regiões frias e chuvosas, com solos de $\mathrm{pH}$ ácido e bem drenados (preferencialmente em encostas de morro) (CARVALHO; ARRUDA, 2011).

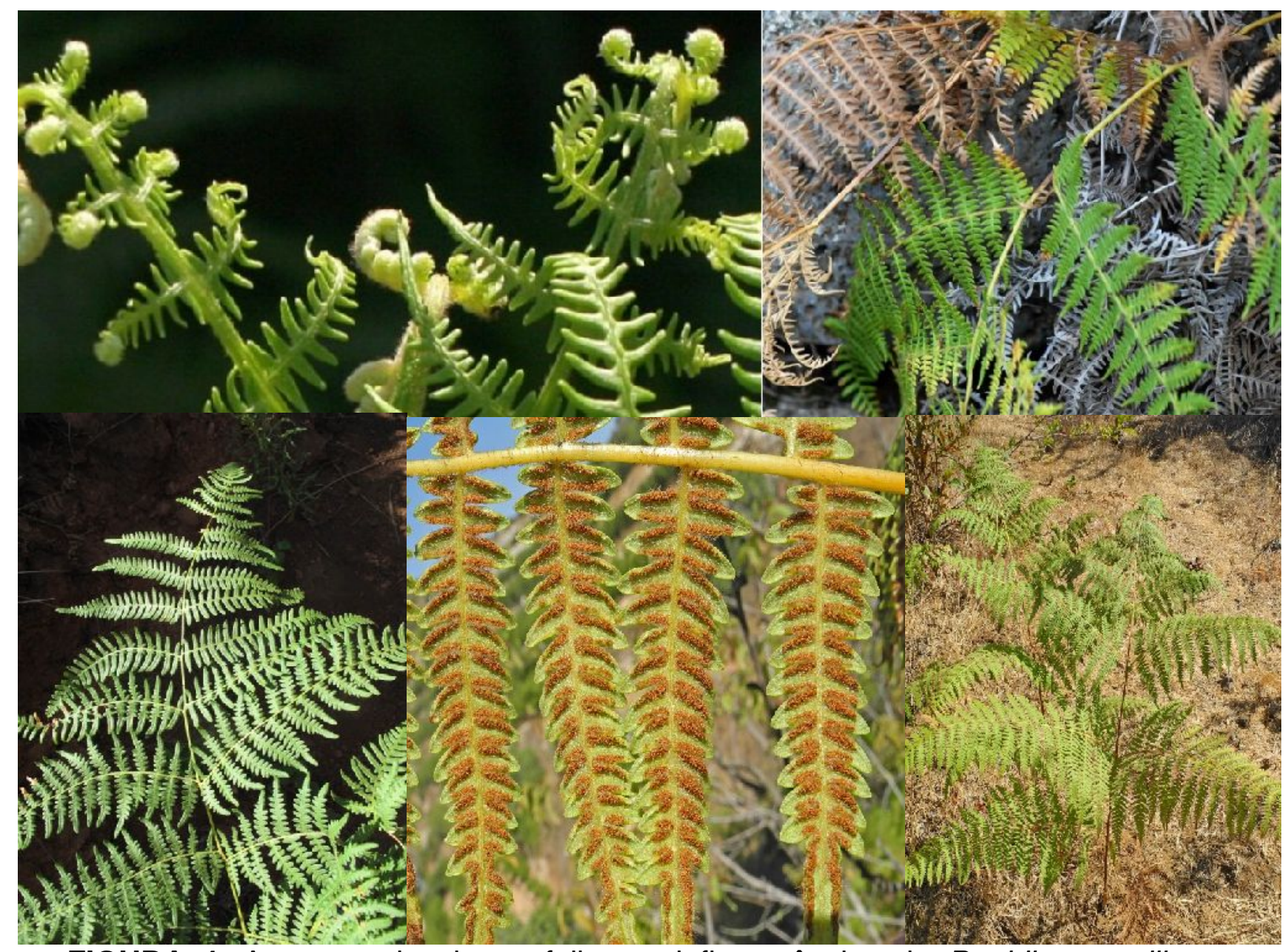

FIGURA 4. Aspectos da planta, folhas e inflorescências de Pteridium aquilinum.

FONTE: Flora of Israel Online (2019). 
A planta é rizomatosa, com folhas grandes de 60 a $180 \mathrm{~cm}$ de comprimento e de 60 a $120 \mathrm{~cm}$ de largura, bipinadas e pode atingir altura de 1,80 metros ou pouco mais (TOKARNIA et al., 2000) e pode causar intoxicação tanto a animais quanto a humanos, sendo considerado um dos vegetais tóxicos mais preocupantes em vários países do mundo, incluindo o Brasil.

De acordo com Ruggieri et al., (2010), o principal fator que leva os animais a ingerirem a planta é a fome. Isto normalmente ocorre em estações secas, pois a planta suporta bem o período sem chuvas, possibilitando sua procura pelos animais O princípio tóxico de $P$. aquilinum é o ptaquilosídeo, um glicosídeo considerado carcinógeno (RINCÓN et al., 2016).

Todas as partes da samambaia contêm os princípios tóxicos em forma ativa, sendo o broto a porção mais tóxica de suas partes aéreas e o rizoma a parte da planta que possui maior atividade carcinogênica (BOABAID et al., 2018). Ao ingerirem folhas ou brotos da planta, os bovinos manifestam perturbações nervosas e podem apresentar manifestações clínicas agudas ou crônicas, destacando-se como principais sintomas: síndrome hemorrágica aguda, hematúria enzoótica e carcinomas nas vias digestórias superiores (CARVALHO; ARRUDA, 2011). A toxidez causada pela planta pode rapidamente matar os bovinos com quadros de diátese hemorrágica ou determinar situações crônicas irreversíveis.

Pertencente à classe das pteridófitas, que são plantas sem sementes, $P$. aquilinum possui dispersão por esporos (GIL FELIPPE, 2009), e também por rizomas. A germinação dos esporos ocorre também na estação seca quanto no verão (GIL FELIPPE, 2009). A ampla distribuição da espécie pode ser atribuída à maior facilidade de dispersão de seus esporos no ar e por permanecerem viáveis por longas distâncias, aliado a um fenótipo que as caracterizam por serem colonizadoras de terrenos cuja vegetação original foi removida ou alterada, tendo como ambiente preferencial as bordas de mata.

Dessa forma, a dispersão anemocórica da espécie, juntamente a uma reprodução vegetativa altamente eficiente são determinantes para o sucesso da $P$. aquilinum como espécie invasora em pastagens. Hojo-Souza et al., (2010) citam ainda que a capacidade invasora das samambaias pertencentes ao gênero Pteridium podem ser explicadas pela resistência natural a condições ambientais adversas, como períodos secos, aliado ao manejo inadequado dos ecossistemas pelo homem.

Considerando os aspectos reprodutivos e fenológicos da espécie, como medidas preventivas à intoxicação com $P$. aquilinum podem ser citadas a erradicação das plantas, eliminando o rizoma e seus rizóides, que estão profundamente enterrados ao solo, o que permite à samambaia resistir às queimadas. Gil Felippe (2009) ressalta que a espécie é resistente à maioria dos herbicidas, de forma que o controle químico deve ser evitado.

\section{Cestrum laevigatum (Schlecht.)}

Cestrum laevigatum é um arbusto da família Solanaceae encontrado nas regiões Sudeste, Centro-Oeste e Nordeste, cujo nome popular é coerana (RUGGIERI et al., 2010). A espécie é uma planta arbustiva que pode ter até três metros de altura, apresentando folhas pecioladas e alternadas, e fruto ovoide, quase preto quando maduro. 


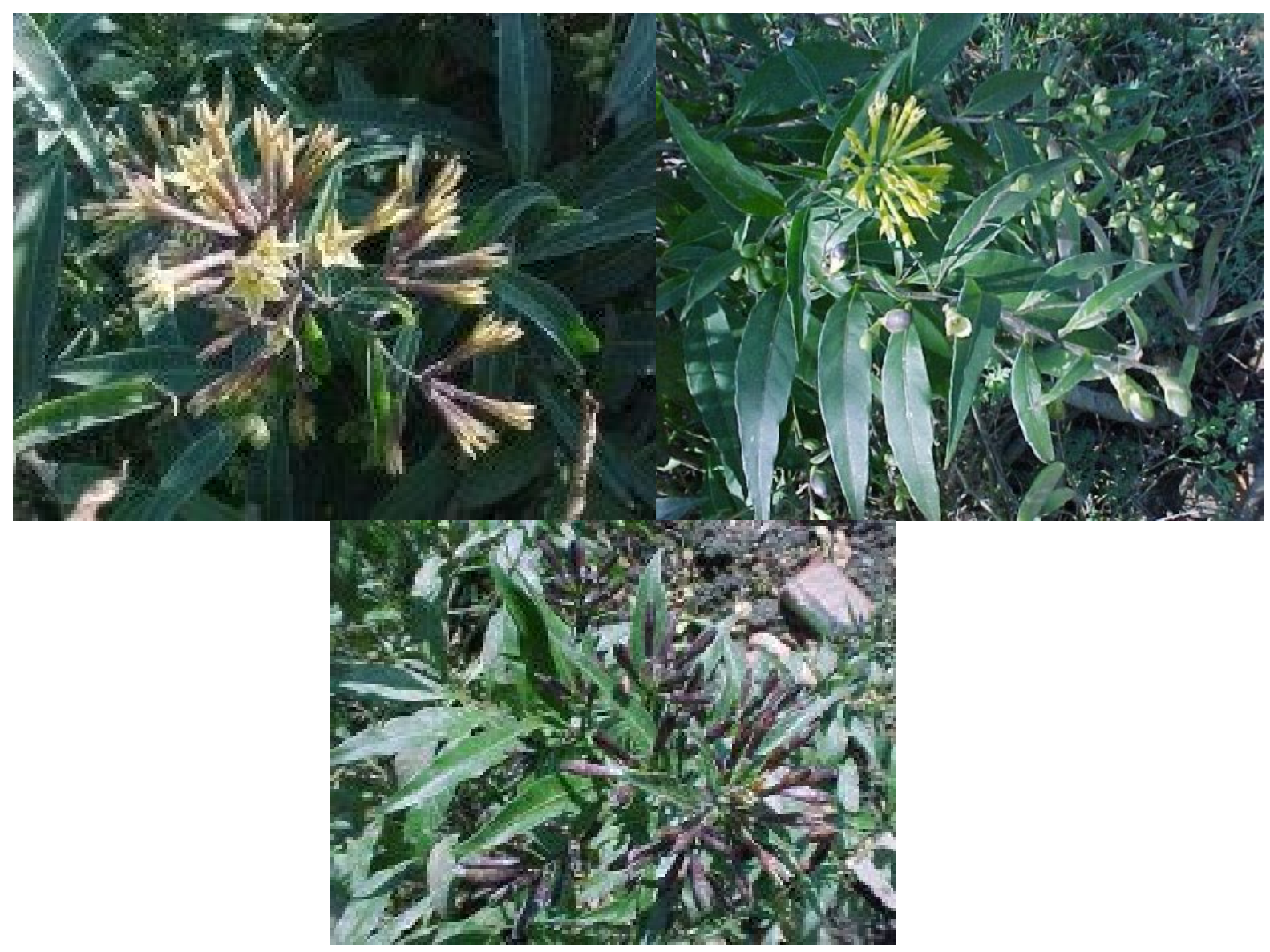

FIGURA 5. Aspectos da planta, folhas e inflorescências de Cestrum laevigatum. FONTE: University of Pretoria (2019).

Cestrum Laevigatum é a planta tóxica mais importante para bovinos no estado do Rio de Janeiro e na região Sudeste, onde encontra-se em áreas não alagadas e em grotas (TOKARNIA et al., 2000), possuindo ampla distribuição e perdas econômicas. As partes tóxicas de $C$. laevigatum são as folhas verdes e brotos, os quais não possuem boa palatabilidade, mas depois de murchos se tornam mais palatáveis (CARVALHO; ARRUDA, 2011).

O princípio tóxico presente em $C$. laevigatum tem sido relatado devido à presença das sapogeninas gitogenina e digitogenina (RIBEIRO et al., 2016). No entanto, a análise fitoquímica do extrato etanólico de $C$. laevigatum permitiu também 0 isolamento de duas saponinas de esqueleto esteroidal [(25R,S)-5 $\alpha$-espirostano$2 \alpha, 3 \beta$-diol-3-O- $\beta$-D-galactopiranosídeo] e $\quad[(25 R, S)-5 \alpha$-espirostan-2 $\alpha, 3 \beta$-diol-3-O- $\beta$ Dgalactopiranosil $(1 \rightarrow 4)-\beta$-D-galactopiranosil $(1 \rightarrow 4)-\beta-D-g l i c o p i r a n o s i l$ (SILVA et al., 2008).

A ingestão da planta pelos animais provoca distrofia hepática centro lombar em bovinos, caprinos e ovinos, sendo alvo da atenção dos criadores que procuram eliminá-las das pastagens (OLIVEIRA NETO et al., 2017). Os sinais clínicos da intoxicação caracterizam-se por anorexia, apatia, tremores musculares, excitação, agressividade, andar cambaleante, constipação, fezes ressecadas contendo muco e sangue, gemidos, sialorreia, focinho seco, sonolência e decúbito esternal (LUGT et al., 1992). Os autores citam que os sinais da intoxicação são observados em 15-24 horas após a ingestão da planta e a morte ocorre entre seis e 48h após o aparecimento dos sinais clínicos.

AGRARIAN ACADEMY, Centro Científico Conhecer - Goiânia, v.6, n.11; p. 255 2019 
A unidade de dispersão de $C$. laevigatum são os frutos, os quais são carnosos indeiscentes de coloração esverdeada e dispersos por zoocoria (SPINA et al., 2001). Os períodos de floração e frutificação da espécie são junho-outubro e fevereirojulho, respectivamente.

A intoxicação pode ser melhor prevenida por meio da erradicação das plantas e dos propágulos reprodutivos, especialmente durante os meses de junho e julho. Além disso, recomenda-se dificultar o acesso de bovinos às folhas e brotos da espécie no solo, principalmente na seca e no início da estação chuvosa, quando pode haver escassez de forragem de boa qualidade (OLIVEIRA NETO et al., 2017).

\section{CONSIDERAÇÕES FINAIS}

Um dos fatores mais importantes para o sucesso da atividade pecuária é a qualidade da pastagem, a qual é muitas vezes afetada, em razão da ocorrência de plantas daninhas, principalmente aquelas que são tóxicas aos animais. Tais plantas, quando ingeridas, podem apresentar significativas consequências negativas à saúde dos bovinos, causadas pela toxicidade dessas plantas.

Nem todas as plantas conhecidas como tóxicas no Brasil possuem elucidados o princípio ativo, as condições ecológicas para crescimento e desenvolvimento da espécie, ou os mecanismos para prevenção e controle das intoxicações. Ainda são escassas informações técnicas sobre as plantas tóxicas de maior importância, assim como os aspectos relacionados à ecofisiologia dessas plantas e aos potenciais riscos aos bovinos.

O estudo das plantas tóxicas apresenta-se como campo potencial para investigação, sendo este conhecimento necessário para desenvolver técnicas mais eficientes de controle das intoxicações por plantas. O controle dessas plantas assume papel extremamente importante na sustentabilidade das pastagens, apresentando reflexo direto no rendimento das forrageiras e na saúde animal. As táticas de controle devem estar inseridas em um sistema de manejo integrado, que interfiram negativamente no estabelecimento e dispersão das plantas tóxicas.

Neste contexto, a compreensão da dispersão das sementes, aliada ao conhecimento das características de regeneração e propagação das plantas apresenta-se como uma ferramenta útil para a conservação/manutenção de áreas sem infestação por estas plantas.

\section{REFERÊNCIAS}

BARBOSA, E. F. G.; CARDOSO, S. P.; CABRAL FILHO, S. L. S.; BORGES, J. R. J.; LIMA, E. M. M.; RIET-CORREA, F.; CASTRO, M. B. Sinais clínicos e patologia da intoxicação crônica experimental de caprinos por Palicourea marcgravii. Pesquisa Veterinária Brasileira, v. 35, n. 3, p. 209-215, 2015. Disponível em:<http://dx.doi.org/10.1590/S0100-736X2015000300001>

BARBOSA, J.D.; OLIVEIRA, C.M.C.; TOKARNIA C.H.; RIET-CORREA, F. Comparação da sensibilidade de bovinos e búfalos à intoxicação por Palicourea marcgravii (Rubiaceae). Pesquisa Veterinária Brasileira v. 23, n. 4, p. 167-172, 2003. Disponível em:<http://dx.doi.org/10.1590/S0100-736X2003000400005>

BATTILANI, J. L. Chuva de sementes em trecho de floresta ripária. Dissertação (Programa de Pós-Graduação em Ecologia e Conservação). Universidade Federal de Mato Grosso do Sul. 173 p. Campo Grande, 2011. Disponível em:< https://www.ibama.gov.br/sophia/cnia/teses/joanicebathilani.pdf> 
BOABAID, F. M.; OLIVEIRA, L. G. S.; DALTO, A. G. C.; BANDARRA, P. M.; SOUZA, F. S.; SONNE, L.; DRIEMEIER, D. Achados clínico-patológicos e métodos de controle da intoxicação por Pteridium (aquilinum) arachnoideum em uma propriedade do Rio Grande do Sul. Pesquisa Veterinária Brasileira, v. 38, n. 8, p. 1584-1596, 2018. Disponível em: < http://dx.doi.org/10.1590/1678-5150-PVB-5709>

BRANDÃO, J. F. C.; MARTINS, S. V.; BRANDÃO, I. J.; LOPES, W. P. Ecological restoration in area dominated by Pteridium aquilinum (L.) Kuhn in Caparaó National Park, MG. Revista Árvore, v. 41, n. 1, p. 1-11, 2017. Disponível em:<http://dx.doi.org/10.1590/1806-90882017000100004>

CARVALHO, G.D; NUNES, L.C; BRAGANÇA, H.B.N.; PORFÍRIO, L.C. Principais plantas tóxicas causadoras de morte súbita em bovinos no Estado do Espírito Santo - Brasil. Archivos de Zootecnia, v.58(R), p. 87-98, 2009. Disponível em:< http://www.uco.es/organiza/servicios/publica/az/php/az.php?idioma_global=0\&revista $=148 \&$ codigo $=1768$

CARDOSO, R. S.; SMILJANIC, K. B. A.; ALMEIDA JUNIOR, J. J.; FUNGHETTO, D. R.; POHLMANN, R. A. C. Plantas tóxicas de importância pecuária na região de Perolândia - GO. In: Anais do II Colóquio Estadual de Pesquisa Multidisciplinar. Mineiros, GO, $2017 . \quad$ Disponível em: <http://publicacoes.unifimes.edu.br/index.php/coloquio/article/view/227>

CARVALHO, G. D.; ARRUDA, V.M. Principais plantas tóxicas causadoras de morte súbita em bovinos. Cadernos didáticos. Viçosa: Universidade Federal de Viçosa, 28 p. 2011.

D'OlIVEIRA, P. S.; BRIGHENTI, A. M.; OLIVEIRA, V. M.; MIRANDA, J. E. C. Plantas Tóxicas em Pastagens: Cafezinho (Palicourea marcgravii St. Hill, Família Rubiaceae). Juiz de Fora, MG: Comunicado Técnico Embrapa 85, 2018a, 10 p. Disponível em:< https://www.embrapa.br/busca-de-publicacoes//publicacao/1095928/plantas-toxicas-em-pastagens-cafezinho-palicourea-marcgraviist-hill-familia-rubiaceae>

D'OlIVEIRA, P. S.; PEIXOTO, P. V.; BRIGHENTI, A. M.; OLIVEIRA, V. M.; MIRANDA, J. E. C. Plantas Tóxicas em Pastagens: Cipó Prata (Amorimia pubiflora, (A. Juss.) W.R. Anderson, Família Malpighiaceae). Juiz de Fora, MG: Comunicado Técnico Embrapa 87, 2018b, 10 p. Disponível em: $<$ https://ainfo.cnptia.embrapa.br/digital/bitstream/item/192514/1/COT-88-Plantas-

Toxicas-Cipo-Prata.pdf>

DIAS-FILHO, M. B. Reclaiming the Brazilian Amazon: the restoration and management of pasture lands. Belém, PA: Embrapa Amazônia Oriental, 2014. 30 p. Disponível em:< https://www.embrapa.br/busca-de-publicacoes//publicacao/988172/reclaiming-the-brazilian-amazon-the-restoration-andmanagement-of-pasture-lands>

DINIZ, K. D.; MACEDO, N. C.; PORTELA, G. F.; REZENDE, L. P. Banco de sementes de plantas daninhas em área de pastagem Panicum maximum Jacq. cultivar Mombaça no município de Balsas - MA. Biodiversidade, v. 16, n. 3, p. 2739 , 2017.

Disponível

em:< 
http://periodicoscientificos.ufmt.br/ojs/index.php/biodiversidade/article/view/6011/388 9>

ESTIMA-SILVA, P.; MOLARINHO, K. R.; MARCOLONGO-PEREIRA, C.; SOARES, M. P.; SALLIS, E. S. V. et al. Morte súbita em bovinos no Sul do Rio Grande do Sul:epidemiologia e diagnóstico. Pesquisa Veterinária Brasileira, v. 36, n. 1, p. 1923, 2016.

Disponível

em:<

https://ainfo.cnptia.embrapa.br/digital/bitstream/item/141908/1/Morte-subita-em-

bovinos.pdf>

FERNANDES, R. D. Estudo fitoquímico de Justicia wasshauseniana (Acanthaceae), Tetrapterys acutifolia e Lophanthera lactescens (Malpighiaceae) e atividades biológicas. Tese (Programa de Pós-Graduação em Química) - Universidade Federal Rural do Rio de Janeiro, Seropédica-RJ, 2016. 203 p.

Flore de Guyane (2016). Disponível em:< https://floredeguyane.piwigo.com/picture?/24547>

Flora of Israel Online (2019). Disponível em:<https://flora.org.il/en/plants/pteaqu/>

FRANCISCHINI, C. R. D.; OLIVEIRA, F. B.; PEREIRA, L. C. S.; SILVA, S. A. Levantamento das principais plantas tóxicas de interesse pecuário para bovinos de corte no município de Rio Verde. Global Science and Technology, v. 11, n. 03, p. 77-85, 2018.2 Disponível em:< https://rv.ifgoiano.edu.br/periodicos/index.php/gst/article/view/1023/620>

GAVA, A.; CRISTANI, J.; BRANCO, J. V.; NEVES, D.S.; MONDADORI, A.J.; SOUSA, R.S. Mortes súbitas em bovinos causadas pela ingestão de Mascagnia sp. (Malpighiaceae), no Estado de Santa Catarina. Pesquisa Veterinária Brasileira v. 18, n. 1, p. 16-20, 1998. Disponível em:< http://dx.doi.org/10.1590/S0100736X1998000100003>

GIL FELIPPE, M.C.T. Venenosas: plantas que matam também curam. São Paulo: Editora Senac São Paulo, 2009. 352 p.

GONZALEZ, G. J. D. Plantas tóxicas de importancia en salud y producción animal en Colombia. Bogotá: Universidad Nacional de Colombia, 2010, 244 p.

HELAYEL, M.A.; FRANÇA, T.N.; SEIXAS, J.N.; NOGUEIRA, V.A.; CALDA, S.A.; PEIXOTO, P.V. Morte súbita em bovinos causada pela ingestão de Pseudocalymma elegans (Bignoniaceae) no município de Rio Bonito, RJ. Pesquisa Veterinária Brasileira v. 29, n. 7, p. 498-508, 2009. Disponível em:< http://dx.doi.org/10.1590/S0100-736X2009000700003>

HOJO-SOUZA, N.S.; CARNEIRO, C.M.; SANTOS, R.C. Pteridium aquilinum: o que sabemos e o que ainda falta saber. Bioscience Journal, v. 26, n. 5, p. 798-808, 2010. Disponível em:< http://www.seer.ufu.br/index.php/biosciencejournal/article/view/7239>

IKEDA, F. S.; INOUE, M. H. Manejo sustentável de plantas daninhas em 
sistemas de produção tropical. Brasília, DF : Embrapa, 2015, 117 p.

JACOBI, C.M.; CARMO, F.F. do. Life-forms, pollination and seed dispersal syndromes in plant communities on ironstone outcrops, SE Brazil. Acta Botanica Brasilica. v. 25, n. 2, p. 395-412, 2011. Disponível em:< http://dx.doi.org/10.1590/S0102-33062011000200016>

KOETHER, K.; LEE, S. T.; BELLUCI, R. S.; JAMES, R. G.; CUNHA, H. J.; ROCHA, N. S.; OLIVEIRA-FILHO, P. Spontaneous poisoning by Palicourea marcgravii (Rubiaceae) in a sheep herd in southeastern Brazil. Toxicon, v.161, n. 1, p. 1-3, 2019. Disponível em:<https://doi.org/10.1016/j.toxicon.2019.02.015>

LUGT, J.J.; VAN DER NEL, P.W.; KITCFFLNG, J.P. Experimentally-induced Cestrum laevigatum (Schlecht.) poisoning in sheep. Onderstepoort Journal of Veterinary Research, v. 59, p. 135-144, 1992. Disponível em:< https://pdfs.semanticscholar.org/aaa4/bedacd1d5bf336112c10272efea5e5f004c3.pdf $>$

MACHADO, C.G.; COELHO, A.G.; SANTANA, C.S.; RODRIGUES, M. Beija-flores e seus recursos florais em uma área de campo rupestre da Chapada Diamantina, Bahia. Revista Brasileira de Ornitologia, v. 15, n. 2, p. 267-279, 2007. Disponível em:<http://inot.org.br/wp-content/uploads/Beija-

flores_e_seus_recursos_florais_em_uma_\%C3\%A1rea_de_campo_rupestre_da_Ch apada_Diamantina_Bahia.pdf

MENDONÇA, D. R.; JÁCOME, R. G. F.; BORGES, C. M. S.; CERQUEIRA, A. B.; DELDUQUE, B. A. F.; et al.,; Exame físico de bovinos prevenidos com acetamida na intoxicação experimental por Palicourea marcgravii. Revista Acadêmica Ciência Animal, v. 15, n. 2, p. 327-328, 2017. Disponível em:< http://dx.doi.org/10.7213/cienciaanimal.v15iSuppl\%202.17406>

NASCIMENTO, N. C. F.; AIRES, L. D. A.; PFISTER, J. A.; MEDEIROS, R. M. T.; RIET-CORREA, F.; MENDONÇA, F. S. Plantas cardiotóxicas para ruminantes no Brasil. Pesquisa Veterinária Brasileira, v. 38, n. 7, p. 1239-1249, 2018. Disponível em: < http://dx.doi.org/10.1590/1678-5150-PVB-5548>

OLIVEIRA NETO, T. S.; RIET-CORREA, F.; BARBOSA, F. M. S.; SILVA, C. M. B. A.; MARQUES, M. F. S.; NÓBREGA, G. D. Natural and experimental poisoning by Cestrum laevigatum (Solanaceae) among cattle in the Agreste region of Paraíba, Brazil. Semina: Ciências Agrárias, v. 38, n. 5, p. 3123-3132,2017. Disponível em:< http://dx.doi.org/10.5433/1679-0359.2017v38n5p3123>

REFLORA/JBRJ (2016). Disponível em:<http://reflora.jbrj.gov.br/reflora>

RIBEIRO, P. R. V.; ARAÚJO, A. J.; COSTA-LOTUFO, L. V.; BRAZ-FILHO, R.; NOBRE JUNIOR, H. V. et al. Spirostanol glucosides from the leaves of Cestrum laevigatum L. Steroids, v. 106, p. 35-40, $2016 . \quad$ Disponível em:<https://doi.org/10.1016/j.steroids.2015.12.006>

RIET-CORREA, F.; MEDEIROS, R.M.T. Intoxicações por plantas em ruminantes no Brasil e no Uruguai: importância econômica, controle e riscos para a saúde pública. Pesquisa Veterinária Brasileira, v. 21, p. 38-42. 2001. Disponível em:< AGRARIAN ACADEMY, Centro Científico Conhecer - Goiânia, v.6, n.11; p. 259 
http://dx.doi.org/10.1590/S0100-736X2001000100008>

RINCON, D. F.; DÍAZ, G. J.; GARDNER, D. R. Detection of Ptaquilosides in different phenologic stages of Bracken fern (Pteridium aquilinum) and analysis of mik samples in farms with hematuria in Tolima, Colombia. Revista CES Medicina Veterinaria y Zootecnia, v. 11, n. 1, p. 72-77, 2016. Disponível em:<http://www.scielo.org.co/pdf/cmvz/v11n1/v11n1a07.pdf>

ROSSETTI, A. C. P. A.; CORSI, M. Plantas tóxicas de interesse pecuário. ESALQ-USP: Projeto CAPIM - Pesquisa e Extensão; Departamento de Zootecnia. 13 p. 2009. Disponível em: <www.projetocapim.com.br>

RUGGIERI, A.C.; REIS, R.A.; QUEIROZ NETO, A.; BALBOS, D.F. Principais plantas tóxicas que afetam bovinos de corte. In: PIRES, A.V. Bovinocultura de corte volume II. p. 1197-1237. Piracicaba: FEALQ, 2010.

SANCHES, M.N.G.; FERNANDES, R.D.; CARVALHO, R.D.; BRAZ FILHO, R. Estudo fitoquímico das folhas Tetrapteys acutifolia. In: Anais... 63ํㅡ Reunião Anual da Sociedade Brasileira para o Progresso da Ciência. Goiânia: 2011.

SILVA, I.P.; LIRA, R.A.; BARBOSA, R.R.; BATISTA, J.S.; SOTO-BLANCOET, B. Intloxicação natural pelas folhas de Mascagnia rigida (Malpighiaceae) em ovinos. Arquivos do Instituto Biológico, v. 75, n. 2, p. 229-233, 2008. Disponível em:< http://www.biologico.sp.gov.br/uploads/docs/arq/v75_2/silva.pdf>

SPINA, A.P.; FERREIRA, W.M.; LEITÃO FILHO, H.F. Floração, frutificação e síndromes de dispersão de uma comunidade de floresta de brejo na região de Campinas (SP). Acta Botanica Brasilica, v. 15, n. 3, p. 349-368, 2001. Disponível em:<http://dx.doi.org/10.1590/S0102-33062001000300006>

TOKARNIA, C.H.; DÖBEREINER, J.; PEIXOTO, P.V. Plantas Tóxicas do Brasil. Editora Helianthus, Rio de Janeiro. 320p. 2000.
University
of
Pretoria
(2019).
Disponível
em:<

https://repository.up.ac.za/handle/2263/8477?show=full> 